\title{
Between inclusion and exclusion: Teachers' reflections about students with autism in public school
}

\section{Entre a inclusão e a exclusão: reflexões de professores sobre educandos com autismo em escola pública}

\section{Entre inclusión y exclusión: reflexiónes de docentes sobre estudiantes con autismo en escuela pública}

\author{
Yago Melo de Lima1 ${ }^{\text {iD }}$, Tânia Regina Lobato dos $\operatorname{Santos}^{1}$ iD, Rejane de Assis Oliveira Monteiro ${ }^{1}$ (D) \\ ${ }^{1}$ Universidade do Estado do Pará, Belém, Pará, Brasil.
}

Autor correspondente:

Yago Melo de Lima

Email: educadoryago@gmail.com

Como citar: Lima, Y. M., Santos, T. R. L., \& Monteiro, R. A. O. (2021). Between inclusion and exclusion: Teachers' reflections about students with autism in public school. Revista Tempos e Espaços em Educação, 14(33), e14098. http://dx.doi.org/10.20952/revtee.v13i32.14098

\begin{abstract}
This paper writes about the reflections of four ordinary teachers and one special education teacher, of a public school in the school inclusion context. Analyze the reflections in relation to the acceptance and reception of students with Autism Spectrum Disorder (ASD) in the school environment. The problem to be solved is the following: how do the acceptance and reception of students with ASD occur in the school? It configures in a snippet of a qualitative and field research based on Teixeira (2010) and Oliveira (2012), developed in a public school in the municipal education system located in Belém-PA in 2017. The theoretical contribution of the investigation was anchored on Orrú $(2012,2016)$ and Mantoan $(2013,2015)$, that study and research about autism and school inclusion. The reflections of the five teachers reveal alarming situations, such as resistance to accepting and welcoming of students with autism in the school context, because some factors interfere in the classroom and school routine, which calls the need of this space to reflect and revise his pedagogical proposal. However, the research also reveals educational situations that enable the school inclusion.
\end{abstract}

Keywords: Continuing education. Pedagogical practices. Schooling.

\section{RESUMO}

Este artigo versa sobre as reflexões de quatro professores do ensino comum e de uma professora da educação especial, de uma escola pública, em contexto de inclusão escolar. Analisa as reflexões em relação à aceitação e ao acolhimento de educandos com Transtorno do Espectro do Autismo (TEA) em ambiente regular de ensino. A problemática a ser desvendada é a seguinte: como se dá a 
aceitação e o acolhimento de alunos com TEA no espaço escolar? Configura-se em um recorte de uma pesquisa qualitativa e de campo, com base em Teixeira (2010) e em Oliveira (2012), desenvolvida em uma escola pública da rede municipal de ensino, localizada em Belém-PA, em 2017. O aporte teórico da investigação foi ancorado em Orrú $(2012,2016)$ e Mantoan $(2013,2015)$, que estudam e pesquisam sobre autismo e inclusão escolar. As reflexões dos cinco professores revelam que ainda há resistência em relação à aceitação e ao acolhimento de educandos com autismo no contexto escolar, porque alguns fatores interferem no cotidiano da sala de aula e da escola, o que gera necessidade de esse espaço refletir e rever a sua proposta pedagógica. Entretanto, a pesquisa também revela situações educacionais que possibilitam a inclusão escolar.

Palavras-chave: Escolarização. Formação continuada. Práticas pedagógicas.

\section{RESUMEN}

Este artículo aborda las reflexiones de cuatro maestros de educación ordinaria y uma maestra de educación especial, de una escuela pública en el contexto de inclusión escolar. Analiza reflexiones sobre la aceptación y recepción de estudiantes con trastorno del espectro autista (TEA) en un entorno de enseñanza regular. El problema a resolver es el siguiente: ¿cómo ocurre la aceptación y recepción de los estudiantes con TEA en la escuela? Está configurado en un recorte de una investigación cualitativa y de campo, basada en Teixeira (2010) y Oliveira (2012), desarrollada en una escuela pública en el sistema educativo municipal, ubicado en Belém-PA, en 2017. La contribución teórica de la investigación se basó en Orrú $(2012,2016)$ y Mantoan $(2013,2015)$, quienes estudian e investigan sobre el autismo y inclusión escolar. Las reflexiones de los cinco maestros revelan que todavía hay resistencia en relación con la aceptación y recepción de estudiantes con autismo en el contexto escolar, porque algunos factores interfieren en el aula y la rutina escolar, lo que crea la necesidad de que este espacio refleje y revise el su propuesta pedagógica. Sin embargo la investigación también revela situaciones educativas que hacen posible la inclusión escolar.

Palabras clave: Escolarización. Formación continua. Prácticas pedagógicas.

\section{INTRODUÇÃO}

Este artigo é um recorte de uma pesquisa realizada em 2017, acerca da inclusão escolar de educandos com Transtorno do Espectro do Autismo (TEA) em uma escola de ensino regular, da rede municipal de ensino da cidade de Belém-PA. O trabalho objetiva tecer reflexões sobre os dizeres de quatro professores do ensino regular e de uma professora da Sala de Recursos Multifuncionais (SRM) em relação à aceitação e ao acolhimento de educandos com autismo nos espaços pedagógicos da escola (sala comum e SRM). A problemática a ser desvendada é a seguinte: como se dá a aceitação e o acolhimento de alunos com TEA no espaço escolar?

Neste texto, apresentamos e discutimos um extrato de uma das categorias temáticas ${ }^{1}$ da pesquisa: aceitação e acolhimento de aluno com autismo na escola regular, a partir da prática pedagógica de professores do ensino regular e de uma professora do Atendimento Educacional Especializado (AEE).

Por envolver singularidades e subjetividades inerentes ao ambiente escolar, a pesquisa nos provocou a ter atenção aos detalhes, bem como aos elementos subjacentes dos relatos docentes para reflexões e análises posteriores. Por essas razões, configurou-se em uma investigação de abordagem qualitativa e de campo, na perspectiva de Teixeira (2010) e de Oliveira (2012); acerca

\footnotetext{
${ }^{1}$ As categorias temáticas constituem o que denominamos de indicadores de análise, ou seja, fatores, aspectos, elementos do fato ou situação em estudo, que são classificados e reunidos em eixos ou unidades temáticas a partir e com os dados coletados. Essas unidades temáticas podem ser subdivididas para facilitar a organização dos dados. As categorias temáticas podem ser organizadas a partir de palavras-chave, de ideias fundantes ou de temas que aglutinam determinadas situações (Mota Neto \& Oliveira, 2011, p. 164).
} 
de questões sobre o autismo e inclusão escolar, nos assentamos em Orrú $(2012,2016)$ e em Mantoan (2013, 2015).

Na primeira etapa, realizamos observações diretas para verificar a prática pedagógica dos professores com educandos com autismo; na segunda etapa, aconteceram as entrevistas semiestruturadas com os professores e, na terceira etapa, um debate focalizado em aspectos empíricos e teóricos em torno dos dados sistematizados na categoria temática.

Deste modo, o texto desvela a inclusão escolar de educandos com TEA como um processo complexo e repleto de desafios, mas também como uma situação praticável, a qual deve ser encarada de forma responsável e compromissada pelos sistemas de ensino e pelos professores na perspectiva de assegurar o acesso ao ensino e à educação de qualidade às crianças com autismo.

\section{AUTISMO EM CONTEXTO DE INCLUSÃO ESCOLAR}

Ao longo da última década, o quantitativo de pessoas com TEA teve uma ascensão global significativa. Durante a investigação, identificamos que "cerca de $1 \%$ da população mundial - ou um em cada 68 crianças - apresenta algum transtorno do espectro do autismo, e a ocorrência da condição neurológica tem aumentado" (Nações Unidas no Brasil [ONUBR], 2016, p. 1). Conforme o Centro de Controle de Doenças e Prevenção, localizado nos Estados Unidos, em uma publicação oficial do governo norte-americano, em 2018, a cada 59 crianças há uma com autismo (Paiva Junior, 2019). Com esta informação, notamos um aumento na incidência de pessoas com a respectiva singularidade no contexto mundial.

Não há dados precisos que revelem a quantidade específica de crianças com autismo no Brasil. "O que podemos é dizer que o país 'deve ter' ou 'pode ter' aproximadamente 2 milhões de pessoas com autismo, segundo estimativas globais da ONU de $1 \%$ da população ser autista, aproximadamente" (Paiva Junior, 2019, p. 23).

Nos últimos anos, as redes escolares passaram a matricular um elevado número de educandos entre quatro e 17 anos, público da educação especial em classes comuns de ensino. Segundo dados do Censo Escolar da Educação Básica (2018), o número de matrículas passou de $87,1 \%$ em 2014 para 92,1\% em 2018. No Censo de 2019, o número passou para 92,8\% (Instituto Nacional de Estudos e Pesquisas Educacionais Anísio Teixeira, 2020). No que concerne à educação especial, a quantidade de matrículas chegou a 1,2 milhão em 2018, um aumento de 33,2\% se compararmos ao ano de 2014. Ainda de acordo com o Censo Escolar de 2019, "o número de matrículas da educação especial chegou a 1,3 milhão em 2019, um aumento de 34,4\% em relação a 2015" (Instituto Nacional de Estudos e Pesquisas Educacionais Anísio Teixeira, 2020, p. 9). Conforme esses dados, observamos um aumento considerável de matrículas nessa modalidade de ensino.

Por esse motivo, os espaços escolares não devem negligenciar medidas pedagógicas que contemplem os interesses e as necessidades de aprendizagem desses sujeitos; devem acolhê-los e potencializá-los enquanto aprendizes e sujeitos do processo educacional. Perante as referências em destaque, constatamos que a presença de estudantes com deficiência é uma realidade nas redes de ensino da educação básica, bem como de educandos com TEA. Sendo assim, apresentar algumas condições inerentes ao respectivo transtorno de desenvolvimento é fundamental nesta discussão. Segundo Orrú (2016), Léo Kanner foi o primeiro pesquisador a descrever algumas particularidades relacionadas ao autismo infantil.

Na década de 1940, Léo Kanner (1943), um psiquiatra austríaco que residiu nos Estados Unidos, dedicou-se aos estudos e à investigação sobre comportamentos que eram considerados estranhos e muito particulares em algumas crianças. Esses comportamentos assinalavam estereotipias por meio de gestos amaneirados e posições estranhas, além de certa dificuldade no modo de se relacionar com as pessoas que ele percebeu como sendo próprias de um quadro de sintomas apresentados por aquelas crianças (Orrú, 2016, p. 13). 
Ferrari $(2012$, p. 9, 10) acrescenta que "inicialmente encarado como uma forma precoce da esquizofrenia, o autismo infantil seria logo reconhecido por Kanner como uma afeç̧ão autônoma e específica ligada aos primeiros anos da infância". Logo, a maioria das crianças com autismo apresenta traços singulares nos primeiros anos de vida.

No início de seu percurso, precocemente ou em etapas posteriores, a criança com TEA passa a ser percebida com estranheza em seu meio de convivência, em especial no ambiente familiar e escolar. Em várias ocasiões, as pessoas notam situações específicas no comportamento da criança, mas não conseguem associá-las ao quadro de autismo.

Em alguns casos, os comportamentos são percebidos na escola, devido a equipe educacional possuir mais informações em relação à síndrome e conviver com a criança em uma perspectiva diferente do espaço familiar. De imediato, a família não associa as características apresentadas como inerentes ao autismo. Orrú (2016) revela algumas especificidades marcantes do autismo por meio das ideias de Léo Kanner.

Kanner descreveu como características desse grupo de crianças a incapacidade para estabelecer relações com as pessoas, uma série de atrasos e alterações na aquisição e no uso da linguagem e certa obsessão em manter o ambiente intacto junto à tendência de repetir uma sequência limitada de atividades ritualizadas (p. 14).

A dificuldade na relação com outras crianças e adultos, a dificuldade na linguagem, a imutabilidade no ambiente, bem como a repetição de situações do cotidiano são traços comuns em crianças com TEA. As respectivas particularidades emergem no convívio social, porém inúmeras famílias não relacionam ao quadro ou não querem aceitar que a criança pode estar inserida no espectro. Em algumas situações, as escolas ainda são os primeiros espaços que conseguem realizar tal associação.

Vale destacar que o autismo não é uma condição limitante à participação de crianças em escolas, pelo contrário, é uma possibilidade para percebermos que esses ambientes devem conceber o trabalho educacional como um direito de acesso a todos. Para Fávero (2013), a educação inclusiva, ao tratar do acesso de crianças e de adolescentes ao mesmo espaço, tem como objetivo principal garanti-lo ao público com deficiência também. Nessa direção, algumas legislações foram criadas ao longo da última década, com o intuito de assegurar alguns direitos. Segundo a Lei no 12.764 ", art. 3ㅇ, "São direitos da pessoa com transtorno do espectro autista: VI - o acesso: a) à educação e ao ensino profissionalizante; [...]" (Lei no 12.764, 2012, p. 1, 2).

Ainda de acordo com a citada lei, outra prerrogativa importante está destacada no art. 70: "O gestor escolar, ou autoridade competente, que recusar a matrícula de aluno com transtorno do espectro autista, ou qualquer outro tipo de deficiência, será punido com multa de 3 (três) a 20 (vinte) salários - mínimos" (Lei n 12.764, 2012, p. 3).

$\mathrm{O}$ artigo 70 se constitui em um elemento fundamental para a garantia do acesso à educação da pessoa com TEA. Desta forma, as redes escolares precisam trabalhar na perspectiva de traduzir esse direito no cotidiano escolar, sobretudo tentar efetivar o acesso e a permanência desse público no espaço pedagógico, aspecto que ainda se configura como um desafio para a maioria das escolas.

A escola inclusiva precisa ser um ambiente propício para lidar com a diversidade. Receber, acolher e proporcionar um lugar afetivo, onde todos os educandos sejam aceitos, tenham acesso e permanência por meio de atividades pedagógicas que respeitem as suas limitações e estimulem as suas potencialidades. Nesse sentido, Orrú (2012) menciona:

\footnotetext{
2 “Institui a Política Nacional de Proteção dos Direitos da Pessoa com Transtorno do Espectro Autista; e altera o § 3ㅇdo art. 98 da Lei no 8.112, de 11 de dezembro de 1990". (Lei no 12.764, 2012, p. 1).
} 
A escola, em uma perspectiva da educação inclusiva, deve se preparar para uma prática pedagógica na qual tanto a coletividade quanto a individualidade favoreçam o pleno desenvolvimento da aprendizagem do estudante, sem desconsiderar sua singularidade. Para que ele seja um sujeito ativo de sua aprendizagem, é necessário que faça parte do grupo, que se relacione, que participe e compartilhe de todas as atividades desenvolvidas (p. 198).

Para receber todas as crianças, independentemente de suas características, as redes escolares devem estar preparadas pedagogicamente, organizadas em contextos educacionais coletivos. A gestão escolar e a equipe de professores precisam adequar o trabalho pedagógico para contemplar a diversidade de crianças que chega ao espaço escolar, em especial as crianças com deficiência.

É de suma importância que as escolas visem e elaborem um desenho curricular, capaz de suscitar e promover situações pedagógicas alicerçadas nos saberes culturais, interesses e necessidades de aprendizagem dos estudantes. Uma escola que desenvolva ações nessa direção poderá se tornar um ambiente que favoreça a todos com qualidade. Mantoan (2013) destaca:

Em uma palavra, as escolas de qualidade são espaços educativos de construção de personalidades humanas autônomas, críticas, nos quais as crianças aprendem a ser pessoas. Nesses ambientes educativos ensina-se os alunos a valorizar a diferença, pela convivência com seus pares, pelo exemplo dos professores, pelo ensino ministrado nas salas de aula, pelo clima socioafetivo das relações estabelecidas em toda a comunidade escolar - sem tensões, competição de forma solidária e participativa. Escolas assim concebidas não excluem nenhum aluno de suas classes, de seus programas, de suas aulas, das atividades e do convívio escolar mais amplo. São contextos educacionais em que todos têm possibilidade de aprender, frequentando uma mesma e única turma (p. 61).

O trabalho pedagógico direcionado a educandos com TEA necessita ser pensado e discutido pela equipe pedagógica, por meio da organização de um currículo com base nas diferenças humanas, sendo fundamental a compreensão da sala de aula como um ambiente complexo, desafiador, mas possibilitadora de várias pedagogias desencadeadas pelos professores com os alunos, na intenção de construir conhecimentos que tenham sentido em suas vidas. Esse contexto se aproxima da ótica de inclusão escolar de Mantoan (2015):

As escolas inclusivas atendem a todos os alunos sem discriminar, sem trabalhar à parte com algum deles, sem estabelecer regras específicas para planejar, ensinar e avaliar alguns por meio de currículos adaptados, atividades diferenciadas, avaliação simplificada em seus objetivos... pode-se imaginar o impacto da inclusão nos sistemas de ensino! (p. 28).

Desta forma, as escolas passam a trilhar o percurso da inclusão desde o momento em que aceitam todas as crianças independentemente de suas necessidades e/ou deficiências. A partir do momento em que a criança é acolhida com amorosidade, tem as suas limitações e potencialidades conhecidas, sobretudo quando é concebida como sujeito que aprende, a inclusão escolar avança.

\section{REFLEXÕES DE PROFESSORES SOBRE EDUCANDOS COM TEA EM CLASSES COMUNS E EM SALA DE RECURSOS MULTIFUNCIONAIS}

O foco da pesquisa era analisar o trabalho docente no que tange à inclusão de educandos com autismo em uma escola da rede pública e, de maneira específica, neste artigo, abordar a categoria "aceitação e acolhimento do aluno com autismo na escola regular". Nesse sentido, desvendamos um contexto complexo, repleto de significados.

$\mathrm{Na}$ perspectiva de analisar como o processo acontecia na esfera da educação básica, selecionamos cinco professores dos seguintes níveis: ensino fundamental dos anos iniciais, ensino 
fundamental dos anos finais e AEE, sendo quatro do ensino regular e uma professora da SRM. Buscamos observar e analisar os procedimentos pedagógicos adotados nas séries iniciais e finais do ensino fundamental para a inclusão de educandos com TEA. Por essa razão, duas professoras do ensino comum eram das séries iniciais, dois professores eram das séries finais e uma professora da SRM atuava nos dois níveis de ensino. A seguir, podemos visualizar os nomes fictícios, a formação e a idade dos sujeitos.

Tabela 1. Sujeitos da pesquisa

\begin{tabular}{ccc}
\hline Professores & Formação & Idade \\
\hline Norma & Pedagogia & 46 \\
Nazaré & Pedagogia & 42 \\
Rosângela & Pedagogia & 47 \\
Aldo & Artes & 36 \\
Jota & Ciência da Religião & 30 \\
\hline
\end{tabular}

Fonte: dados da pesquisa de campo (2017).

O grupo é predominantemente composto por pedagogas. Os outros professores atuam a partir do 6으 ano do ensino fundamental com disciplinas que requerem a lotação em várias escolas para o preenchimento da carga horária. Entre as pedagogas, duas desenvolvem atividades nas séries iniciais: uma no turno da manhã e tarde, tendo uma turma em cada, e outra somente à tarde, com uma turma - pela manhã, na época da pesquisa, trabalhava em outra instituição escolar. Os professores de Artes e de Ciência da Religião assumem várias turmas, em diferentes espaços, em função da baixa carga horária das disciplinas.

A diferença em relação ao número de turmas que os professores assumem reverbera no contexto da sala de aula, pois as professoras das séries iniciais trabalhavam em duas, já os das outras licenciaturas em várias turmas. Isso contribui para que os docentes de Artes e Ciência da Religião possuam um número elevado de turmas, consequentemente de educandos também.

Como já mencionado, a educação é uma garantia para as crianças com deficiência, em particular a criança com TEA. Na medida em que as escolas recebem esse público de forma acolhedora, com o dever pedagógico de criar, planejar e desenvolver estratégias, podem ser capazes de atender as suas necessidades educacionais. Nesse caminho, a Política Nacional de Educação Especial na Perspectiva da Educação Inclusiva (2008) contribui na discussão para o avanço no processo pedagógico.

A intencionalidade da Política de Educação Especial é para que o público-alvo seja contemplado, e a pessoa com autismo compõe esse público. Conforme as Diretrizes da Política de Educação Especial, as crianças devem ser contempladas com ações pedagógicas que eliminem barreiras para a sua plena participação no processo e que complementem a sua formação, e não que restrinjam a sua participação no espaço educacional, como evidencia a fala do professor Aldo, ao ser questionado sobre o que pensa sobre a presença do aluno com autismo na sala de ensino regular:

Olha só, a questão do aluno com autismo, o que eu penso é assim: tem que levar em consideração a questão da sala de aula em si, entendeu? Por que o quê é que tá se propondo? O quê que vai se propor pra eles? Bom, é muito complicado esse aluno com autismo [...] (Aldo, escola em Belém).

A fala revela um olhar excludente perante a presença de educandos com autismo em sala de aula. A opinião do professor expressa a preocupação com o contexto da sala, e não com a participação dos educandos, como se não fosse possível elaborar estratégias pedagógicas para incluí-los. Há preocupação com o que a escola pode oferecer. Subentendemos que não existem condições específicas para atender esse público, em nível de formação, organização do espaço ou 
do trabalho pedagógico. E ainda que o professor aparenta ter pouca preocupação e formação para envolver os alunos com TEA em sala de aula.

Porém, Mantoan (2015) afirma: "[...] a escola não pode continuar ignorando o que acontece ao seu redor, nem anulando e marginalizando as diferenças nos processos pelos quais forma e instrui os alunos" (p. 22). Dessa maneira, a sociedade conclama por uma escola que realize um trabalho com estratégias pedagógicas aptas a envolver os alunos e possibilitar oportunidades reais de aprendizagem e de desenvolvimento.

Nessa perspectiva, a escola deve repensar e ressignificar suas concepções e medidas educacionais, no intuito de disseminar projetos e metodologias de ensino que promovam práticas pedagógicas inclusivas; um trabalho que reúna, por exemplo, a coletividade, como Mantoan (2015) aponta:

Experiências de trabalho coletivo, em grupos pequenos, mudam esse cenário educativo, exercitando: a capacidade de decisão dos alunos diante da escolha de tarefas; a divisão e o compartilhamento das responsabilidades com seus pares; o desenvolvimento da cooperação; o sentido e a riqueza da produção em grupo; e o reconhecimento da diversidade dos talentos humanos, bem como a valorização do trabalho de cada pessoa para a consecução de metas que Ihes são comuns (p. 70).

A autora apresenta possibilidades pedagógicas, explicando como o processo educacional pode ser realizado no ambiente escolar, de modo que os educandos com autismo também possam ter condições de participar conforme os seus estilos e ritmos de aprendizagem. A partir desse viés pedagógico, é possível vislumbrar oportunidades de aprendizagem para o público em questão, tendo em vista que, para acontecer, é necessário o compromisso da gestão escolar e dos professores.

Conhecer e trabalhar com uma nova proposta pedagógica poder gerar insegurança e incerteza. Nessa via, uma das professoras relatou como foi receber um educando com TEA em sala de aula:

Eu, eu particularmente não tinha ainda vivenciado essa experiência de trabalhar com uma criança autista. Então, eu tenho nos últimos três anos consecutivos, que eu comecei a trabalhar com criança autista. Então pra mim, foi logo no início, foi bem chocante, eu confesso que eu fiquei um pouco perdida, porque eu não sabia nem por onde começar, e aí, pra mim, no primeiro ano mesmo que, eu sou professora aqui, eu já vou fazer vinte anos só de carreira, mas com autismo, eu comecei a trabalhar há três anos atrás. Então pra mim, foi bem difícil o início, até porque eu não tinha ainda é, conhecimento mesmo, né? (Nazaré, escola em Belém).

A fala revela uma professora com longa experiência docente, porém somente há três anos passou a conviver com o autismo em sala de aula. Ela relata que o início do processo foi desafiador e aterrorizante, principalmente pela falta de fundamentação teórico-metodológica e formação acerca do assunto, o que dificultava a sua atuação. Segundo Freire (2016): "é próprio do pensar certo a disponibilidade ao risco, a aceitação do novo que não pode ser negado ou acolhido só porque é novo [...]" (p. 36). Isso significa que receber e acolher os educandos diante de todas as suas singularidades humanas, e não criar perfis seletivos para delimitar quem será recebido e acolhido é essencial no espaço escolar.

Na perspectiva da inclusão escolar, as redes educacionais devem reinventar os seus projetos pedagógicos para ressignificar as suas metodologias de ensino, os processos de aprendizagem e as avaliações classificatórias vivenciadas pelos educandos. Mantoan (2015) provoca: "as escolas inclusivas propõem um modo de organização do sistema educacional que considera as necessidades de todos os alunos, estruturado em função dessas necessidades" (p. 28). As escolas interessadas e 
compromissadas com o sucesso educacional de seus educandos elaboram e realizam um trabalho pedagógico conforme os seus interesses e necessidades, para alcançar avanços e superar fracassos.

Há alguns anos, a discussão em torno da inclusão escolar tem sido fomentada no cenário político, social e, em especial, escolar. Um dos objetivos seria desencadear condições de trabalho apropriadas para a concretização de um ambiente educacional apto ao acolhimento e à realização de práticas pedagógicas que atendam às necessidades dos educandos. Entretanto, ainda existem alguns entraves, como um dos sujeitos da investigação aponta em relação à presença do aluno com autismo em sala de aula:

Na minha opinião deveria ter uma estrutura mais preparada pra gente poder atender esse aluno. Você percebe que colocar um aluno com autismo, dependendo do grau do autismo, em uma turma com 40 alunos, em uma sala com estrutura física precária, sem ventilação, sem nenhum tipo de apoio pra esse aluno, é complicado. Aí, acaba que a gente não consegue dar atenção necessária pra esse aluno, principalmente pelo tempo que é corrido também. A gente tem que repassar o conteúdo, a gente tem que é, tentar fazer com que o aluno preste atenção na aula da maneira mais, da melhor maneira possível e acaba que o tempo, a estrutura, tudo isso acaba prejudicando (Jota, escola em Belém).

O professor relata uma situação frequente na rede pública de ensino: a enturmação dos alunos. O elevado quantitativo de educandos em uma classe regular interfere diretamente no processo de aprendizagem, principalmente da criança com TEA, considerando a estrutura do espaço, condição fundamental para a sua participação no trabalho pedagógico.

Em diversas situações, os professores apresentam desafios para acompanhar o percurso de aprendizagem de seus educandos, sobretudo quando há quarenta em uma turma. Por esse motivo, a enturmação também precisa ser problematizada no âmbito escolar, com o intuito de que os agentes dos sistemas de ensino reflitam e revejam para tornar as salas de aula ambientes propícios ao processo de ensino e de aprendizagem com qualidade.

Mantoan (2015) afirma: "certamente, um professor que participa da caminhada do saber com os alunos consegue entender melhor as dificuldades e possibilidades de cada um" (p. 78). Isso representa que os espaços escolares devem reorganizar a enturmação, com a intenção de promover um trabalho educacional no qual professores estejam atentos e conheçam os itinerários de aprendizagem dos educandos, para que seus interesses e necessidades sejam contemplados.

A reorganização dos ambientes educacionais da escola deve agregar também a discussão sobre a sala de ensino regular enquanto um lugar de aprendizagem para todos, e não como sinônimo de exclusão de alunos com autismo, como se o AEE fosse o único espaço pedagógico a ser frequentado por estes. Tal visão é revelada pelo seguinte professor:

E a outra, a outra questão, é a questão do que se propõe de fato. O que você quer? Socializar com os alunos somente, entendeu? Porque tem certas habilidades nos outros alunos que é complicado, porque se o professor tem uma turma de 40 alunos e, dentro desses 40 , ele tem um aluno autista, e isso levando em consideração que esse professor regente, que essa professora, ela tem no máximo uma turma de manhã e uma turma à tarde, se for um professor como eu, um professor horista, que tem 21 turmas. Só aqui, eu tenho 16, manhã e tarde, é complicado, porque tu, às vezes, o que tu tá passando, eu tô falando de um conteúdo que esse aluno, ele não tem a menor percepção, entendeu? Então acaba sendo essa realidade. Na minha opinião, acaba sendo, não tendo um objetivo para ele, se tivesse um atendimento especializado corpo a corpo, entendeu? Corpo a corpo, eu acho que seria mais interessante (Aldo, escola em Belém).

O sujeito considera a classe comum somente como um espaço de socialização, e não como um lugar cujo educando com autismo possa ter os seus aspectos cognitivos estimulados. Alega a 
impossibilidade de participação desse aluno, pelo fato de não ter a compreensão do conteúdo ministrado, bem como pelo fato de ter inúmeras turmas para dar conta na sua rotina de docente horista.

É pertinente salientar a quantidade de turmas em que o professor desenvolve suas atividades, realidade de vários professores nas redes educacionais de ensino, pois, por essa razão, não conseguem conhecer o público de suas aulas, os ritmos e os estilos de aprendizagem. Na maioria das situações, a preocupação é voltada apenas à transmissão do conteúdo, e não para o processo de aprendizagem, como o caso do alunado com TEA.

Referente ao trabalho especializado, a partir da fala do professor, subentendemos que deveria haver uma dinâmica que envolvesse todo o processo de ensino e de aprendizagem dos alunos com autismo; a substituição dos procedimentos educacionais que deveriam ser realizados na classe de ensino regular para a SRM. No âmbito educacional, é fundamental que professores conheçam, valorizem e estimulem o potencial dos seus educandos, especialmente quando estes apresentam um estilo peculiar, como as pessoas englobadas no espectro do autismo.

Orrú (2012) ratifica que a criança com autismo deve ser concebida como aprendente, sem que deixemos de observar o desenvolvimento dos aspectos biológico, social, cultural e histórico, e demais particularidades que a constituem integralmente. No contexto escolar, a sua aprendizagem deve ser conectada a esses fatores, além de ser/estar aliada às experiências cotidianas e sociais da criança.

É primordial que diálogos entre a equipe pedagógica aconteçam permanentemente nas redes educacionais, com a finalidade de esclarecer e reforçar as atribuições dos ambientes de ensino e de aprendizagem da escola (sala de ensino regular/SRM), no que tange ao processo pedagógico de alunos com TEA, para que os professores conduzam o seu fazer-pedagógico em vista da inclusão.

A maioria das narrativas evidencia que a professora da SRM, responsável pela realização do $\mathrm{AEE}$, demonstra aceitação à presença dos alunos com autismo em classes de ensino regular.

Eu acho de extrema importância, a presença do aluno com deficiência dentro do espaço da sala regular, independente de ser autista ou ser uma outra deficiência. Pela experiência, né? Pela nossa vivência na sala de recurso multifuncional e dentro duma escola municipal, a gente vê que a criança que vem pra esse espaço, seja criança com deficiência ou a criança com transtorno do autismo ou qualquer outro tipo de transtorno, ela progride significativamente, quando ela tá no espaço de sala de aula regular (Rosângela, escola em Belém).

O relato da professora do AEE revela um olhar diferenciado, esperançoso para a inclusão escolar de pessoas ainda negligenciadas pelos sistemas educacionais hegemônicos, como as com autismo, pois ela acredita ser essencial a presença desse público em classe comum e afirma que a criança, ao ingressar na sala de aula comum, apresenta progressos significativos.

No contexto educacional, a participação de docentes como a professora do AEE é importante, pois ela apresenta uma linha de pensamento inclusivo e demonstra aceitação da criança com autismo e pessoas com outras necessidades de aprendizagem. Além do mais, o seu discurso é materializado na prática pedagógica, como observamos:

[...] a gente costuma trabalhar materiais que favoreçam a coordenação motora, a identificação de cores, identificação de animais, a identificação da sequência numérica, a sequência de vogais, famílias silábicas e construção de palavras simples. Então, a gente vem do mais simples pro mais complexo, como com qualquer outra criança, como com qualquer outro indivíduo no desenvolvimento da aprendizagem dele. A gente vai trabalhando com o aluno autista desse jeito, né? (Rosângela, escola em Belém). 
Identificamos que a docente realiza atividades educacionais, de estímulo à coordenação motora até à construção de palavras, fundamentais para a aprendizagem de alunos com TEA; atividades imprescindíveis para o seu desenvolvimento, como forma de complementação pedagógica para a potencialização do trabalho a ser realizado em classe comum.

Por essa via, a inclusão escolar passa a ter sentido quando o discurso é materializado em ações educacionais que proponham práticas capazes de estabelecer um vínculo afetivo e pedagógico entre educandos-educandos e educandos-educadores. Por esse ângulo, de acordo com Mantoan (2015): "a inclusão implica uma mudança de perspectiva educacional, pois não atinge apenas alunos com deficiência e os que apresentam dificuldades de aprender, mas todos os demais, para que obtenham sucesso na corrente educativa geral" (p. 28).

A mudança de perspectiva educacional pode acarretar avanços para o espaço escolar, com uma proposta pedagógica de cunho inclusivo, divergente do sistema de ensino tradicional, responsável pela marginalização e exclusão de pessoas sem deficiência e, principalmente, de pessoas com deficiência. Nesse viés, a escola deve subverter o padrão educacional enraizado há anos, a fim de que haja uma roupagem pedagógica que acolha e inclua todos.

Todavia, devemos ponderar contrapontos entre os relatos da professora especializada e dos professores de ensino regular, já que não apresentam a mesma linha de pensamento em vista da aceitação e de acolhimento de educandos com autismo no ambiente escolar.

Notamos em alguns relatos dos professores da classe regular de ensino um olhar excludente quanto à presença do respectivo público no meio escolar, como se não fosse possível desencadear uma proposta pedagógica que envolvesse as necessidades de aprendizagem, em decorrência do número elevado de estudantes em sala de aula, da falta de experiência com autismo e da estrutura física precária da rede escolar. Ao contrário disso, acreditamos que esses aspectos devem ser repensados e superados nas escolas, pois acarretam interferências no processo educacional de todos, e não podem ser determinantes para a presença de educandos com TEA e/ou outras deficiências.

É indispensável desconstruir esse olhar, o qual impossibilita a aceitação, o acolhimento e as possibilidades de aprendizagem de educandos com autismo, sobretudo na classe de ensino comum. Machado (2009) propõe que os educadores abandonem as metodologias transmissivas, o domínio enfático dos conteúdos curriculares e o ensino livresco como únicas ferramentas pedagógicas, pois não favorecem as necessidades educacionais dos estudantes.

Essa ótica educacional pode disseminar práticas pedagógicas que não potencializem as habilidades de alunos com TEA, porque não concebem as suas singularidades de aprendizagem ao longo do trabalho educacional. Por isso, eles não acompanham o ritmo da sala de aula, o que provoca a sua exclusão.

Por outro lado, a professora da SRM apresenta um olhar sensível no que diz respeito às crianças com autismo. No entanto, nas narrativas dos professores de ensino regular, não percebemos que os educandos avançam, como enfatizado por ela. Tal contradição demonstra que os espaços educacionais, ensino regular e AEE, caminham em direções distintas, situação que pode prejudicar a inclusão das crianças com TEA.

Nessa situação, o processo educativo no espaço da pesquisa é percebido por olhares contrários à proposta de inclusão escolar. Conforme Machado (2009):

A forma de conceber o ensino e a aprendizagem está atrelada às concepções de currículo, e a organização curricular que faz parte da grande maioria das escolas é aquela que estrutura o conhecimento escolar em disciplinas. Também faz parte dessa organização as turmas divididas em séries e a manipulação dos tempos e dos espaços do cotidiano escolar, pois o tempo de aprender está estruturado de acordo com as convenções da escola e não com o tempo dos alunos. Todo esse tipo de organização dificulta a consolidação da escola inclusiva. As disciplinas escolares passam a ser o único meio de conhecimento. Realmente, sob essa lógica, a entrada de 
alunos com deficiência nas salas de aula comuns causa uma série de transtornos para as convenções escolares (p. 99).

A estrutura escolar, verdadeiramente, ainda precisa ter a preocupação com o tempo de aprender dos educandos. Em diversas situações, não percebemos relação entre a teoria e a prática no desenvolvimento das atividades pedagógicas, o que inviabiliza o sucesso na trajetória educacional de alunos, sobretudo os que apresentam autismo.

Machado (2009) enfatiza que os professores do ensino regular precisam caminhar pedagogicamente, em consonância com essa concepção de processo de ensino e de aprendizagem, para garantir a inserção e a participação dos educandos com deficiência no contexto social.

\section{ALGUMAS CONSIDERAÇÕES}

A pesquisa apresentou resultados que necessitam ser problematizados, pois revelam questões que implicam a falta de compromisso pedagógico com os educandos com TEA na escola. Entretanto, é fundamental acreditar que o processo de inclusão escolar é um acontecimento possível, porque ainda há professores comprometidos com o fazer-pedagógico e que contribuem com a aprendizagem e o desenvolvimento de seus alunos com autismo.

Os relatos dos professores, no que tange à aceitação e ao acolhimento de educandos com autismo devem ser problematizados, discutidos, refletidos e repensados, a fim de que os alunos com deficiência tenham a garantia de acesso e de permanência na escola, além da visibilização como sujeitos aprendentes no processo pedagógico.

Um fator a ser apontado é em relação ao quantitativo de alunos por turma e a diferença entre o número de turmas das professoras das séries iniciais e as turmas dos professores que atuam a partir do 60 ano. Para estes, o processo apresenta maiores desafios em virtude do quantitativo elevado de turmas para o preenchimento da carga horária. Como precisam ter um número significativo de horas-aula, têm mais dificuldades, pois não conseguem se preparar e conhecer, de fato, os educandos, principalmente aqueles com deficiência.

Uma questão a ser revista está relacionada às barreiras atitudinais dos professores, que inviabilizam a realização de práticas pedagógicas efetivas para a inclusão dos educandos. A postura tradicional ainda é predominante nos docentes, o que dificulta o acolhimento e a inclusão em situações de aprendizagem, ou seja, as barreiras atitudinais são entraves habituais no trabalho pedagógico dos professores nas escolas.

Nesse quadro, a necessidade de formação continuada é um aspecto fundamental na discussão, uma vez que o texto revela que os professores ainda precisam de subsídios para compreender e lidar com os educandos com TEA, uma responsabilidade que as secretarias e as escolas não estão assegurando a contento. Sendo assim, isso reflete de maneira negativa no processo de aprendizagem, já que os professores não conseguem promover metodologias condizentes com as necessidades educacionais dos seus alunos com deficiência.

Outra situação inquietante, observada nos relatos, é a divergente ação e compreensão pedagógica entre a professora da SRM, que acredita no desenvolvimento de educandos com autismo no contexto da classe de ensino regular, fator que merece destaque na perspectiva da inclusão, e os demais professores, que não percebem a situação do mesmo modo. Ou seja, notamos uma contradição entre as ações pedagógicas na escola, o que provoca consequências no desenvolvimento dos educandos.

Sendo assim, mediante o cenário educacional apresentado no espaço de investigação, é fundamental reestruturar e ressignificar as redes de ensino, com o intuito de estabelecer uma linha de abordagem pedagógica capaz de garantir a inclusão escolar. Uma maneira disso acontecer pode ser por meio da reformulação da proposta pedagógica, que deve inserir pedagogias ativas, gestão compartilhada e democrática, que provoque mudanças nas concepções dos professores, em 
consonância com ações pedagógicas que respeitem, valorizem e potencializem os diferentes estilos e ritmos de aprendizagem, o trabalho coletivo entre os educandos, bem como o estimulo à amorosidade, ao diálogo e à solidariedade na realização das atividades.

Contribuiçães dos Autores: Lima, Y. M.: concepção e desenho, aquisição de dados, análise e interpretação dos dados, redação do artigo, revisão crítica relevante do conteúdo intelectual; Santos, T. R. L.: concepção e desenho, aquisição de dados, análise e interpretação dos dados, redação do artigo, revisão crítica relevante do conteúdo intelectual; Monteiro, R. A. O.: concepção e desenho, aquisição de dados, análise e interpretação dos dados, redação do artigo, revisão crítica relevante do conteúdo intelectual. Todos os autores leram e aprovaram a versão final do manuscrito.

Aprovação Ética: Não aplicável.

Agradecimentos: Não aplicável.

\section{REFERÊNCIAS}

Fávero, E. A. G. (2013). Alunos com deficiência \& seu direito à educação: trata-se de uma educação especial? In: Mantoan, M. T. E. O desafio das diferenças nas escolas (5a ed.). Petrópolis: Vozes, p. 17-27.

Ferrari, P. (2012). Autismo infantil: o que é \& como tratar? (4a ed.). São Paulo: Paulinas.

Freire, P. (2016). Pedagogia da autonomia: saberes necessários à prática educativa (54a ed.). Rio de Janeiro: Paz e Terra.

Instituto Nacional de Estudos e Pesquisas Educacionais Anísio Teixeira (Inep). Censo da Educação Básica 2019: notas estatísticas. (2020). Brasília.

https://download.inep.gov.br/publicacoes/institucionais/estatisticas_e_indicadores/notas_ statisticas_censo_da_educacao_basica_2019.pdf

Lei № 12.764, de 27 de dezembro de 2012. Institui a Política Nacional de Proteção dos Direitos da Pessoa com Transtorno do Espectro Autista. Diário Oficial da União (DOU) de 28 de dezembro de 2012. (2012). Brasília. https://www.jusbrasil.com.br/diarios/45243736/dou-secao-1-28-12-2012-pg-2

Machado, R. (2009). Educação especial na escola inclusiva: políticas, paradigmas \& práticas. São Paulo: Cortez.

Mantoan, M. T. E. (2013). Ensinando a turma toda: as diferenças na escola. In: Mantoan, M. T. E. O desafio das diferenças nas escolas. (5a ed.). Petrópolis: Vozes, p. 59-67.

Mantoan, M. T. E. (2015). Inclusão escolar - o que é? Por quê? Como fazer? São Paulo: Summus.

Nações Unidas no Brasil. (2016). Rejeitar pessoas com autismo é 'um desperdício de potencial humano', destacam representantes da ONU. https://brasil.un.org/pt-br/72685-rejeitar-pessoas-com-autismo-e-um-desperdicio-depotencial-humano-destacam-representantes-da

Notas Estatísticas: Censo Escolar 2018. (2019). Brasília.

https://download.inep.gov.br/educacao_basica/censo_escolar/notas_estatisticas/2018/notas_estatisticas_censo_esc olar_2018.pdf.

Oliveira, I. A., \& Mota Neto, J. C. (2011). A construção de categorias de análise na pesquisa em educação. In: Marcondes, M. I., Oliveira, I. A., \& Teixeira, E. Abordagens teóricas \& construções metodológicas na pesquisa em educação. (22a ed.). Belém: EDUEPA, p. 161-179.

Oliveira, M. M. (2012). Como fazer pesquisa qualitativa (4aed.). Petrópolis: Vozes.

Orrú, S. E. (2016). Aprendizes com autismo: aprendizagem por eixos de interesse em espaços não excludentes. Petrópolis: Vozes.

Orrú, S. E. (2012). Trajetória, avanços \& desafios na concepção \& educação de educandos com autismo. In: Orrú, S. E. Estudantes com necessidades especiais: singularidades \& desafios na prática pedagógica inclusiva. Rio de janeiro: Wak Editora, p. 177-204.

Paiva Junior, F. (2019). Quantos autistas há no Brasil? Revista Autismo, 4(4), 20-23.

https://www.alex.pro.br/tea_revista_4.pdf

Política Nacional de Educação Especial na Perspectiva da Educação Inclusiva. (2008). Brasília.

http://portal.mec.gov.br/arquivos/pdf/politicaeducespecial.pdf 
Teixeira, E. (2010). As três metodologias: acadêmica, da ciência \& da pesquisa (7ạ ed.). Petrópolis: Vozes.

Recebido: 23 de julho de 2020 | Aceito: 4 de maio de 2021 | Publicado: 24 de maio de 2021

This is an Open Access article distributed under the terms of the Creative Commons Attribution License, which permits unrestricted use, distribution, and reproduction in any medium, provided the original work is properly cited. 